\title{
TO STUDY THE RISK OF CARDIOVASCULAR MORBIDITY \& MORTALITY IN STABLE COPD PATIENTS BASED ON ESTABLISHED CARDIOVASCULAR RISK FACTORS IN CENTRAL INDIA
}

Ravindra Chordiya ${ }^{1}$, Satish Motiwale ${ }^{2}$, Prakash Joshi ${ }^{3}$

\section{HOW TO CITE THIS ARTICLE:}

Ravindra Chordiya, Satish Motiwale, Prakash Joshi. "To Study the Risk of Cardiovascular Morbidity \& Mortality in Stable COPD Patients Based on Established Cardiovascular Risk Factors in Central India". Journal of Evolution of Medical and Dental Sciences 2014; Vol. 3, Issue 10, March 10; Page: 2434-2444,

DOI: $10.14260 /$ jemds/2014/2156

ABSTRACT: The epidemiologic evidence linking COPD and cardiovascular morbidity and mortality is strong. Even after adjustments for traditional cardiovascular risk factors such as serum total cholesterol hypertension, obesity and smoking, patients with COPD have a two- to threefold increase in the risk of cardiovascular events including death. Age $>60$ yrs., Male sex, Significant Smoking History, T2 Diabetes Mellitus, Body Mass Index $>30 \mathrm{Kg} / \mathrm{M} 2$, Left Ventricular Hypertrophy have a statistically significant correlation to cardiovascular mortality \& morbidity. Significant relations were demonstrated between the treatment that patient requires for stability \& cardiovascular morbidity \& mortality in Central India.

KEYWORDS: COPD.

INTRODUCTION: Chronic obstructive pulmonary disease (COPD) can result from several etiologies, most importantly cigarette smoke, which can affect the lung by several distinct mechanisms. ${ }^{1} \mathrm{COPD}$ affects approximately 5 per cent of adults in India. ${ }^{2,3}$ The prevalence rates in male subjects of $2.12 \%$ to $9.4 \%$ in studies reported from North India are generally higher than $1.4 \%$ to $4.08 \%$ reported from South India. 4

DEFINITION OF COPD: Chronic Obstructive Pulmonary Disease (COPD) is a preventable and treatable disease with some significant extra pulmonary effects that may contribute to the severity in individual patients. Its pulmonary component is characterized by airflow limitation that is not fully reversible. The airflow limitation is usually progressive and associated with an abnormal inflammatory response of the lung to noxious particles or gases. ${ }^{4,5}$

Cigarette smoke and other environmental irritants and infectious organisms may activate alveolar macrophages, bronchial epithelial cells, and other cellular elements in the airways of genetically susceptible individuals. ${ }^{4-8}$

MATERIAL \&METHODS: The present study entitled "To Study the Risk of Cardiovascular Morbidity \& Mortality in Stable COPD Patients Based on Established Cardiovascular Risk Factors" was undertaken at Department Of Respiratory Diseases, SAMC, Indore, a tertiary care referral center.

METHODOLOGY: Study Design: An Institutional based case control study.

Study Setting: Department of Respiratory Diseases, SAMC, Indore.

Study Period: Two years extending from Dec 2012 to Dec 2013. 


\section{Inclusion Criteria:}

A] CASE:

COPD was diagnosed by premorbid pulmonary function testing when available. In the absence of documented airflow obstruction we used clinical criteria, clinical history with compatible physical findings and/or evidence of hyperinflation on chest radiograph in support of the diagnosis of COPD as described in 1987 statement from American Thoracic Society.1,3,5 In patients with COPD, acute exacerbation was diagnosed if the following criteria ${ }^{1,3}$ were present:

(i) Recent rapid worsening of dyspnea

(ii) Increase in sputum purulence; and

(iii)Increase in sputum volume

B] CONTROL: Patients referred to dept. of pulmonary medicine for pre-operative Pulmonology clearance with no known established or past history of chronic respiratory illness.

C] Patient's residing in Central India.

\section{Exclusion Criteria:}

1. Patients with primary pathology like bronchial asthma, bronchiectasis and restrictive lung disease like kyphoscoliosis.

2. Patients with established history of Rheumatic, Congenital, Ischemic heart disease, Valvular heart diseases, coronary artery disease and chronic liver \& kidneys diseases.

3. Patients with pre-existing structural lung diseases, lung cancer \& critically ill, active pulmonary Koch's and established

4. Immunosuppressive patients [ HIV positivity, malignant diseases, organ transplant patients, on chemotherapy ]

5. Patients on prolonged statin therapy

6. Patients presenting with infective exacerbations, frank purulent expectoration

7. History of pneumonic illness in past 1 month

8. Patients older than 75 yrs. of age.

Data Collection: A total of 200 COPD cases attending Department Of Respiratory Diseases, SAMC, Indore OPD and Emergency room were screened from which 100 patients were selected randomly, studied clinically, lipid profile analysis, CRP, electrocardiographically, pulmonary function test. Patients were investigated when their condition stabilized, before they were discharged, after obtaining informed consent.

A detailed history was taken in all patients, particularly focused on symptoms related to respiratory system, smoking, environmental exposure, presence or absence of co-morbid factors.

STUDY RESULTS: The present study entitled "Study of Cardiovascular morbidity \& mortality in Stable COPD on the basis of established cardiovascular risk factors." was conducted in the Department Of Respiratory Diseases, SAMC, Indore.

Total number of patients studied (n): 200

Total no of controls - 20 
The following are our observations on analyzing the results of the study:

\begin{tabular}{|c|c|c|}
\hline GOLD STAGE & MALE & FEMALE \\
\hline 1 & 10 & 5 \\
\hline 2 & 32 & 9 \\
\hline 3 & 27 & 4 \\
\hline 4 & 11 & 2 \\
\hline \multicolumn{2}{|c|}{ Demography of the Study } \\
\hline
\end{tabular}

The study comprised of $80 \%$ males \& $20 \%$ females with the majority of the study population formed the GOLD STAGE 2 COPD patients which were nearly $41.5 \%$ of the total study group.

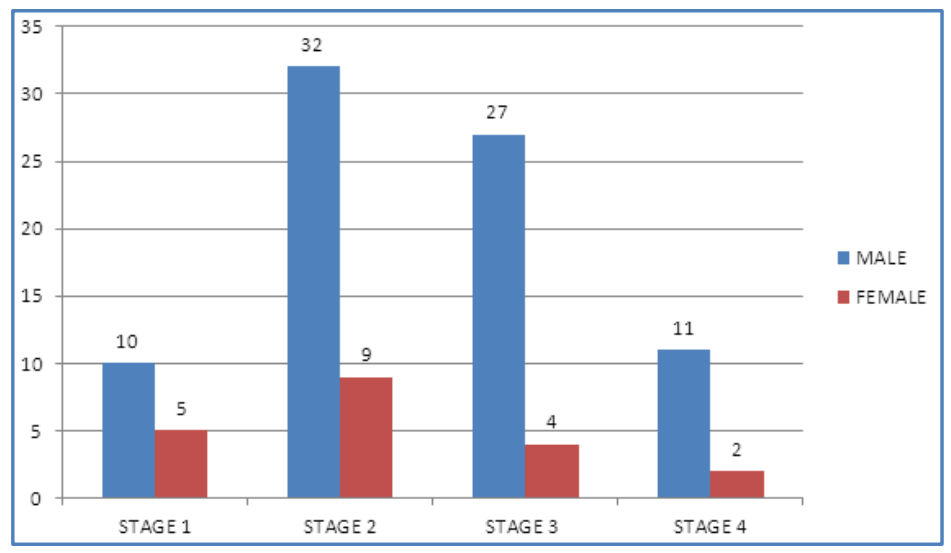

\begin{tabular}{|c|c|c|}
\hline AGE & MALE & FEMALE \\
\hline $50-60$ & 29 & 4 \\
\hline $61-70$ & 22 & 10 \\
\hline $71-80$ & 29 & 6 \\
\hline \multicolumn{3}{|c|}{ Age Distribution } \\
\hline
\end{tabular}

Nearly all of the patients were above 50 yrs. of age \& all being post-menopausal females. Average age of male subjects was $66.84 \pm 7.40 \mathrm{yrs}$.

Average age of female subjects was $68.19 \pm 5.40 \mathrm{yrs}$.

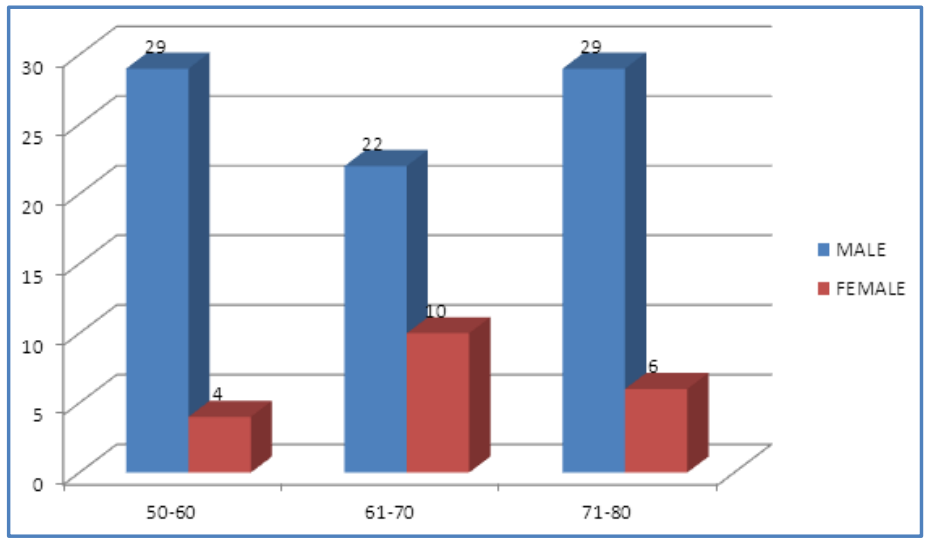




\begin{tabular}{|c|c|c|}
\hline GOLD Stage & Male & Female \\
\hline 1 & 31.14 & 31.55 \\
\hline 2 & 26.72 & 26.42 \\
\hline 3 & 24.16 & 28.28 \\
\hline 4 & 20.116 & 25.15 \\
\hline \multicolumn{3}{|c|}{ BMI DISTRIBUTION } \\
\hline
\end{tabular}

BMI distribution was homogenous amongst all the four groups with an average BMI of $25.34 \pm 6.7$ in males \& $27.85 \pm 9.2$ in females. The BMI was found to be gradually decreasing as per increasing severity of the COPD. Average weight of male subjects was $64 \pm 25.75 \mathrm{~kg}$ and average weight of female subjects was $60.75 \pm 20.12 \mathrm{~kg}$. Average height of male subjects was $1.62 \pm 0.4 \mathrm{~m}$ and average height of female subjects $-1.560 \pm 0.3 \mathrm{~m}$. The study group comprised of 100 individuals [female and males, mean age of yrs., BMI kg/m2]. The waist \& height of the study population was $34.091 \pm 5.2689$ inches, $1.6 \pm 0.09 \mathrm{~m}$ respectively with the maximum waist size being 53 inches.The maximum weight of the study group was $112 \mathrm{~kg}$ with a mean of $68.615 \pm 17.8 \mathrm{~kg}$.

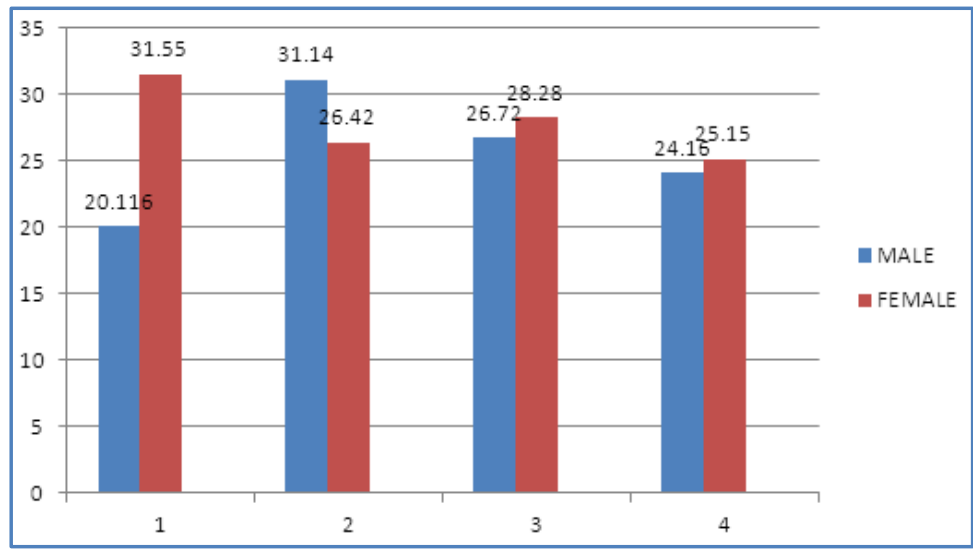

\section{RELATION OF OBESITY TO CARDIOVASCULAR MORTALITY \& MORBIDITY:}

The odds ratio for the morbidity of cardiovascular disease was 1.365 [0.5825-3.5301] with a $\mathrm{p}$ value $=0.5199$ while the odds ratio for the mortality of cardiovascular diseases is 0.5833 [0.21981.5483] with a p value $=0.2791$. hence no significant relation in COPD patients could be demonstrated between obese \&non-obese stable COPD patients though it was observed that with increasing severity COPD patients usually have lower BMI.

\begin{tabular}{|c|c|c|}
\hline BMI [Kg/m2] & non-obese [<30] & obese [>30] \\
\hline CVD Morbidity & 15.8039 & 22.1726 \\
\hline CVD Mortality & 32.35325 & 49.37391 \\
\hline
\end{tabular}




\section{ORIGINAL ARTICLE}

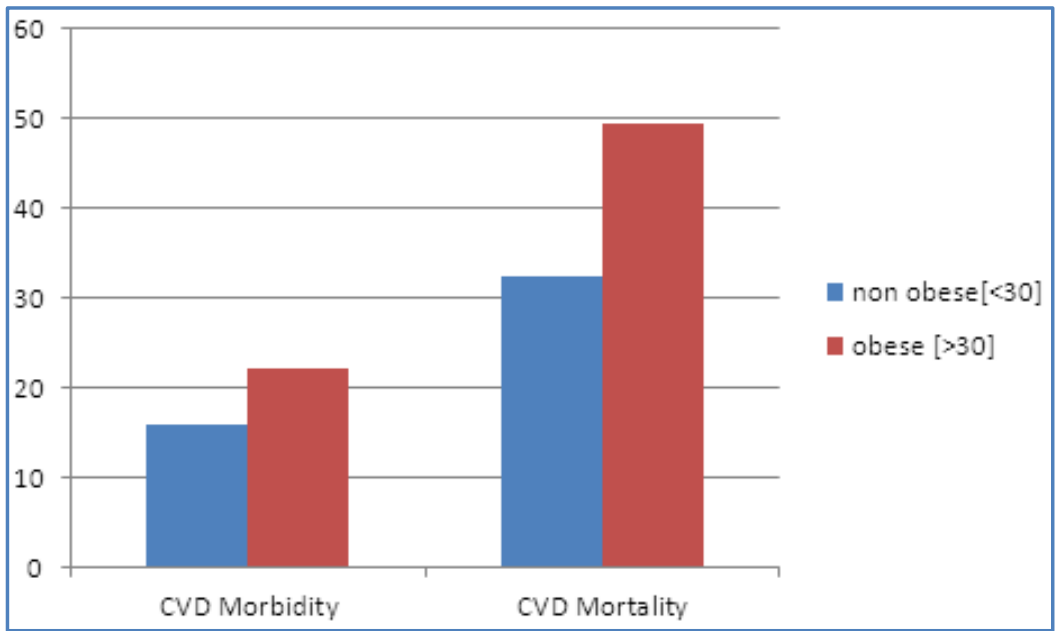

\begin{tabular}{|c|c|c|c|}
\hline & Males & Females & Quantification \\
\hline Alcoholics & 14 & & \\
\hline Current smoker & 70 & & 24.9 pack years \\
\hline Quit then started & 10 & & \\
\hline Chronic ex Old smoker & 40 & & \\
\hline Bidi smoker & 40 & & SI 1365 \\
\hline Chulha gas exposure & - & 6 & \\
\hline
\end{tabular}

History of addiction was found predominantly in males. Tobacco Smoking \& alcoholism were the major identifiable type of abuse substances., with incidence of smoking $70 \%$ with $57 \%$ using bidi with an average Smoking index of 1365 \& cigarette smokers with an average of 24.9 pack years.

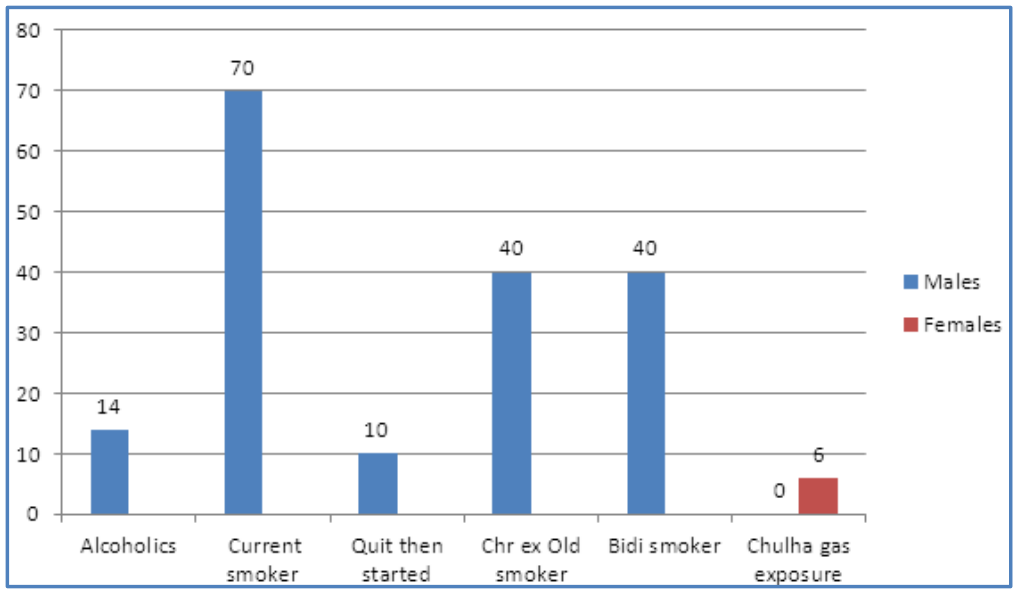

Statistical Significance Could Be demonstrated into the Cardiovascular Morbidity \& Mortality $\&$ Smoking History by the ANOVA analysis $[\mathrm{p}<0.05]$. 


\begin{tabular}{|c|c|c|}
\hline Duration of smoking & CVS MORTALITY & CVS MORBIDITY \\
\hline 10 & 10.1 & 21.55 \\
\hline 20 & 18.14 & 20.42 \\
\hline 30 & 26.72 & 20.28 \\
\hline$>30$ pack yrs. & 33.16 & 28.15 \\
\hline Non-Smokers & 5.6 & 6.7 \\
\hline \multicolumn{2}{|c|}{ Correlation to Smoking \& CVD risk } \\
\hline
\end{tabular}

A statistically significant relationship is demonstrated between the duration of smoking \& the incidence of cardiovascular mortality \& morbidity.

\begin{tabular}{|c|c|c|}
\hline GOLD STAGE & MALE & FEMALE \\
\hline 1 & 7 & 1 \\
\hline 2 & 15 & 7 \\
\hline 3 & 16 & 4 \\
\hline 4 & 4 & 2 \\
\hline \multicolumn{2}{|c|}{ Systemic Hypertension } \\
\hline
\end{tabular}

14 of the 20 Female Stable COPD patients were hypertensive with a relatively higher incidence in Stage 3 \& 4 COPD subgroups. The incidence in male COPD's was nearly 52.5\% with a higher incidence in stage 3 subgroup.

\begin{tabular}{|l|c|c|c|c|c|}
\hline GOLD STAGE & $\mathbf{1}$ & $\mathbf{2}$ & $\mathbf{3}$ & $\mathbf{4}$ & CTRL \\
\hline MALE & 18.42 & 20.14 & 29.44 & 66.5 & 7.01 \\
\hline FEMALE & 15.69 & 13.08 & 30.74 & 83.00 & 6.89 \\
\hline \multicolumn{7}{|c|}{ CRP DISTRIBUTION } \\
\hline
\end{tabular}

An average of $83.00 \& 66.5 \mathrm{mg} \%$ was found in GOLD STAGE 4 males \& females respectively as compared to an average of $28.63 \pm 1.1 \mathrm{mg} \%$ in the study population.

In the control group a few individuals had disproportionately higher CRP values' but were not considered for sake of statistical accuracy and were attributed to subclinical infection in the control population.

ANOVA analysis \& Dunnet test applied on the study population revealed a statistically significant \& positive correlation between Serum CRP levels number of cardiovascular risk factors \& COPD severity $[\mathrm{p}<0.05]$.

Various medical co morbidities were observed which were usually common in this age group but are not documented risk factors for cardiovascular mortality or morbidity .In the male subset BPH \& APD were documented with high frequency while in the female subset a higher incidence of depression \& RA was observed. 


\begin{tabular}{|l|c|c|c|c|}
\hline GOLD STAGE & $\mathbf{1}$ & $\mathbf{2}$ & $\mathbf{3}$ & $\mathbf{4}$ \\
\hline Male & 7 & 18 & 13 & 4 \\
\hline Female & 4 & 5 & 1 & 2 \\
\hline
\end{tabular}

Diabetes Mellitus Type 2 Distributions

An average incidence of $44 \%$ was observed in the study population.

In the GOLD STAGE 4 female COPD subset both the females had Type 2 diabetes mellitus \& GOLD STAGE 1 male COPD subset nearly 7 of the 10 study subset patients had type 2 diabetes mellitus.

\begin{tabular}{|l|c|c|}
\hline \multicolumn{1}{|c|}{ 2 D ECHO FINDING } & MALES & FEMALE \\
\hline Left Ventricular Hypertrophy & 40 & 9 \\
\hline LV Dysfunction & 15 & 2 \\
\hline RV Dysfunction & & \\
\hline Cor Pulmonale [RA, RV DILATION] & & \\
\hline Mild & 26 & 8 \\
\hline Moderate & 17 & 1 \\
\hline Severe & 16 & 2 \\
\hline Valvular heart disease & 2 & 5 \\
\hline Pulmonary hypertension & 33 & 10 \\
\hline Pericardial disease & 1 & - \\
\hline \multicolumn{2}{|c|}{ 2 D ECHOCARDIOGRAM } \\
\hline
\end{tabular}

The most common 2 D ECHO abnormalities in males were LVH [50\%], Cor Pulmonale [59\%] $\&$ in females was Cor Pulmonale [55\%]

\begin{tabular}{|c|c|c|c|c|}
\hline GOLD STAGE & $\mathbf{1}$ & $\mathbf{2}$ & $\mathbf{3}$ & $\mathbf{4}$ \\
\hline Male & 5 & 15 & 14 & 6 \\
\hline Female & 2 & 5 & 1 & 1 \\
\hline Left Ventricular Hypertrophy Distribution \\
\hline
\end{tabular}

Relatively higher incidence of Left ventricular hypertrophy was seen in male GOLD STAGE 4 COPD patients \& females of GOLD STAGE 2.

\begin{tabular}{|c|c|c|}
\hline Family history & Males & Female \\
\hline Yes & 42 & 10 \\
\hline No & 38 & 10 \\
\hline \multicolumn{2}{|c|}{ Family history } \\
\hline
\end{tabular}

A positive family history of cardiovascular diseases amongst first degree relatives was elicited in $50 \%$ of the female subject population \& $51 \%$ of the male COPD subset. 
A uniform distribution of positive family history was demonstrated between all the study groups and control group hence no statistical significance could be demonstrated to the incidence of cardiovascular risk factors \& COPD.

\begin{tabular}{|l|c|c|c|c|c|c|}
\hline \multicolumn{1}{|c|}{ Treatment codes } & Treatment & $\mathbf{N}$ & Morbidity & p value & Mortality & p value \\
\hline 1. InhaledAnticholinergics & 1 & 5 & 29.96 & 0.54 & 9.313333 & 0.41 \\
\hline 2. LABA & $1+2$ & 15 & 15.61897 & 0.38 & 10.32759 & 0.30 \\
\hline 3. ICS & $1+2+3$ & 56 & 27.5 & 0.16 & 12.375 & 0.28 \\
\hline 4. ORAL BRONCHODILATOR & $1+2+3+4$ & 70 & 42.78108 & 0.67 & 16.85405 & $<0.001$ \\
\hline 5. ORAL STEROIDS & $1+2+3+4+5$ & 47 & 47.5875 & $<0.001$ & 21.0125 & $<0.001$ \\
\hline 6. H.O.T & $1+2+3+4+5+6$ & 7 & 48.63333 & $<0.0001$ & 19.43333 & $<0.0001$ \\
\hline 7. HMG Co-A Reductase inhibitors & 7 & 20 & 28.180 & 0.69 & 26.85405 & 0.39 \\
\hline
\end{tabular}

Treatment related cardiovascular mortality \& morbidity

The analysis of the COPD patients and its correlation to the treatment being taken by them Reveal that a statistically significant relation to mortality \& morbidity [ $p<0.0001]$ is demonstrated in patients on oral steroids \& Home oxygen therapy. No, significant association to mortality \& morbidity was demonstrable between other established treatment modalities.

\begin{tabular}{|l|c|c|c|c|}
\hline \multicolumn{1}{|c|}{ Column1 } & STAGE 1 & STAGE 2 & STAGE 3 & STAGE 4 \\
\hline MORBIDITY[\%] & 35.19 & 33.85 & 38.84 & 38.48 \\
\hline MORTALITY[\%] & 14.12 & 13.77 & 13.47 & 14.88 \\
\hline CRP [meq/L] & 17.51 & 19.21 & 29.73 & 67.46 \\
\hline
\end{tabular}

Stage Wise Distribution of CVD, MI, CVD Mortality \& Se CRP Levels

\begin{tabular}{|c|c|c|}
\hline GOLD STAGE & MALE & FEMALE \\
\hline 1 & 1.2 & 1.2 \\
\hline 2 & 1.0625 & 0.44 \\
\hline 3 & 1.111 & 1 \\
\hline 4 & 1.0909 & 1.00 \\
\hline
\end{tabular}

Relative Risk of Cardiovascular Morbidity

The relative risk of cardiovascular morbidity was observed in the various GOLD stages with the highest risk observed in the STAGE 1 Male \& female subgroups [RR 1.2, p $0.0023 \mathrm{f}$ 0.01].Statistically significant risks of morbidity as compared to the control group was observed in GOLD stage $3 \& 4$ [p $<0.05$ respectively] .

ANOVA analysis determines a statistically significant association between increasing severity of Stage of COPD and Cardiovascular morbidity.

\section{RELATIVE RISK OF CARDIOVASCULAR MORTALITY IN COPD:}

\begin{tabular}{|c|c|c|}
\hline GOLD STAGE & MALE & FEMALE \\
\hline 1 & 1.0 & 0.64 \\
\hline 2 & 0.8750 & 0.356 \\
\hline
\end{tabular}




\section{ORIGINAL ARTICLE}

\begin{tabular}{|l|c|c|}
\hline 3 & 1.111 & 0.800 \\
\hline 4 & 1.0909 & 0.800 \\
\hline
\end{tabular}

CVS mortality over a period of ten years was evaluated and demonstrated to be higher in all GOLD STAGES particularly in STAGE 1, 3\& 4. Statistically significant differences were observed in all male subsets of the study \& in female stage $3 \& 4$.

ANOVA above mentioned subset failed to reveal a statistically significant association in between the increasing severity of COPD \&Cardiovascular mortality.

On comparison of individual groups using the Dunnet test a statistically significant and higher mortality could be demonstrated in between stages $3 \& 4$. The CVS mortality was comparable in between the control and stage $1 \& 2$ COPD patients.

\begin{tabular}{|l|c|c|}
\hline \multicolumn{1}{|c|}{ RISK FACTORS } & CVD morbidity & CVS Mortality \\
\hline Age & 2.26 & 2.00 \\
\hline Male Sex & 1.116 & 1.3 \\
\hline HIGH TOTAL CHOL $[>200 \mathrm{mg} / \mathrm{dl}]]$ & 1.274 & 1.1 \\
\hline LOW HDL CHOL $[<40 \mathrm{mg} / \mathrm{dl}]$ & 1.0036 & 1 \\
\hline LVH & 0.3376 & 0.458 \\
\hline DM2 & 0.7178 & 0.65 \\
\hline HTN & 0.4920 & 0.481 \\
\hline SE CRP & 0.9566 & 0.98 \\
\hline FAMILY H/O & 1.03 & 1.04 \\
\hline SMOKING & 1.2810 & 1.46 \\
\hline FEV1 & 1.61 & 1.5 \\
\hline BMI [> 30 kg/m2] & 1.316 & 1.3 \\
\hline Alcoholics & 0.4209 & 0.184 \\
\hline \multicolumn{2}{|c|}{ Comparison of Cardiovascular Risk Factors In Stable COPD } \\
\hline
\end{tabular}

With respect to cardiovascular morbidity an unpaired t test revealed a statistically significant association with Age, Left ventricular hypertrophy, Systemic hypertension, Serum C Reactive protein, Smoking \& alcohol. With respect to cardiovascular mortality an unpaired t test revealed a statistically significant association with Age, Left ventricular hypertrophy, Systemic hypertension, Serum C Reactive protein, Smoking. On comparison of the various risk factors individually statistically significant association to an increased risk of cardiovascular morbidity \& mortality was seen with Left Ventricular Hypertrophy [p value < 0.0001]. An increased relative risk in morbidity \& mortality was also observed in with risk factors like Age, Hypertension, Serum CRP, and Left Ventricular

\section{DISCUSSION:}

A] Comparative analysis of Cardiovascular Mortality \& Morbidity: Various studies have reported a strong link between the occurrence of COPD and the presence of CAD. The causal link between these diseases has historically been cigarette smoking, but the exact mechanisms have only recently been studied. Epidemiologic evidence supports the importance of systemic inflammation in the 
pathogenesis of atheroma formation and ischemic heart disease, and recent studies have indicated that patients with COPD have a prominent systemic inflammatory response. ${ }^{1-5}$

The anatomical and functional relation that exists between the lungs and the heart is such that any dysfunction that impacts in one of the organs is likely to have consequences on the other. ${ }^{9}$

This may be possibly because patients with COPD tend to have higher incidence of CAD due to persistent raised systemic inflammatory status of the individual.5-9 This is the possibility in view of which patients from our study were also evaluated with CRP to further document this raised inflammation.

The present study conducted an estimated CVS mortality of 1.5 in males and 1.4 in females respectively. The study population was composed of 100 patients with $66 \%$ males and an average age 0 f 65.63 years.

Stage wise analysis of the relative risk of cardiovascular morbidity was compared with various studies which revealed, relative risk of cardiovascular risk factors in patients $[<0.01 \mathrm{p}$ value $>0.001]$.

\begin{tabular}{|c|c|c|}
\hline GOLD STAGE & D.M. MANNINO ET AL & Present study \\
\hline Control & 1 & 1 \\
\hline 1 & 2.4 & 1.2 \\
\hline 2 & 1.7 & 0.68 \\
\hline 3 & 2.2 & 1.3 \\
\hline 4 & 2.4 & 1.5 \\
\hline
\end{tabular}

Patients in Stage 1 COPD had a relatively higher mortality as compared to Stage 2 since they were not on any regular treatment or taking any specific precautions for cardiovascular complications, as they might be unaware of their ongoing severity of the disease process.

Patients with advanced COPD [stage 3, 4] and on home oxygen therapy, on oral bronchodilator \& steroid therapy have an heightened mortality as compared to early COPD or patients on ICS/LABA/ACS which substantiates the findings of our study that have an heightened mortality as compared to early COPD or patients on ICS/LABA/ACS which substantiates the findings of our study that there is an raised cardiovascular morbidity associated with an worsening COPD status. In the lung health study, for every $10 \%$ decrease in FEV1, cardiovascular mortality increases by about $28 \%$, and nonfatal coronary event increases by about $20 \%$ in mild to moderate COPD.

CONCLUSIONS: The epidemiologic evidence linking COPD and cardiovascular morbidity and mortality in Central India is strong.

Even after adjustments for traditional cardiovascular risk factors such as serum total cholesterol hypertension, obesity and smoking, patients with COPD have a two- to threefold increase in the risk of cardiovascular events including death.

The following conclusions could be made from the study,

1. Age $>60$ yrs., Male sex, Significant Smoking History, T2 Diabetes Mellitus, Body Mass Index > $30 \mathrm{Kg} / \mathrm{M} 2$, have a statistically significant correlation to cardiovascular mortality \& morbidity.

2. Se CRP levels provide a useful indicator for assessment of severity of cardiovascular morbidity \& mortality in Stable COPD patients. 
3. Significant relations were demonstrated between the treatment that patient requires for stability \& cardiovascular morbidity \& mortality.

4. Weight reduction, Exercise, antiplatelet \& hypolipidemic drugs should be given adequate stress in the management of Stable COPD patients.

5. Cardiovascular disease is an important but undertreated cause of COPD morbidity \& mortality $\&$ should be addressed to improve overall COPD outcome.

\section{REFERENCES:}

1. Murray \& Nadal. Obstructive airway diseases , 4th ed. USA : Elsiever ; 1995.

2. Global Strategy for the Diagnosis, Management, and Prevention of Chronic Obstructive Pulmonary Disease (2006).

3. S.K.Chabra et al. Chronic Obstructive Pulmonary Disease and Cardiovascular Disease, Indian J Chest Dis Allied Sci 2006; 48: 95-96 ed. India: University Of Delhi; 1995.

4. S.K. Jindal et al . Guidelines for Management of Chronic Obstructive Pulmonary Disease (COPD) in India: A Guide for Physicians (2003). Indian Journal of Chest \& Allied Sciences 2004; 46(1): 137-153.

5. Murthy et al. Economic burden of chronic obstructive pulmonary disease, NCMH Background papers - Burden of disease in India;264-270.

6. Anthonisen NR, Connett JE, Enright PL, Manfreda J. Lung Health Study Research Group. Hospitalizations and mortality in the Lung Health Study. Am J Respir Crit Care Med2002; 166: 333-9.

7. Mannino DM, Homa DM, Akinbami LJ, Ford ES, Redd SC. Chronic obstructive pulmonary disease surveillance: United States, 1971-2000. MMWR Surveill Summ2002; 51: 1-16.

8. Murray CJ, Lopez AD. Global mortality, disability, and the contribution of risk factors: Global Burden of Disease Study. Lancet1997; 349: 1436-42.

9. Celli BR, MacNee W, Agusti AG, Anzueto A, Berg BR, Buist AS, Calverley P, Chavannes N, Dillard T, Fahy B et al. Standards for the diagnosis and treatment of patients with COPD: a summary of the ATS/ERS position paper. Eur Respir J 2004;23:932-946.

\section{AUTHORS:}

1. Ravindra Chordiya

2. Satish Motiwale

3. Prakash Joshi

\section{PARTICULARS OF CONTRIBUTORS:}

1. Professor and HOD, Department of Chest Medicine, Sri Aurobindo Institute of Medical Sciences \& Post Graduate Institute, Indore.

2. Associated Professor, Department of Chest Medicine, Sri Aurobindo Institute of Medical Sciences \& Post Graduate Institute, Indore.

3. Senior Registrar, Department of Chest Medicine, Sri Aurobindo Institute of Medical Sciences \& Post Graduate Institute, Indore.

\section{NAME ADDRESS EMAIL ID OF THE} CORRESPONDING AUTHOR:

Dr. R. Chordiya,

Department of Respiratory Diseases, SAMC \& PGI,

Indore.

E-mail: deptoftbcsaims@yahoo.in

Date of Submission: 11/02/2014.

Date of Peer Review: 12/02/2014.

Date of Acceptance: 19/02/2014.

Date of Publishing: 04/03/2014. 